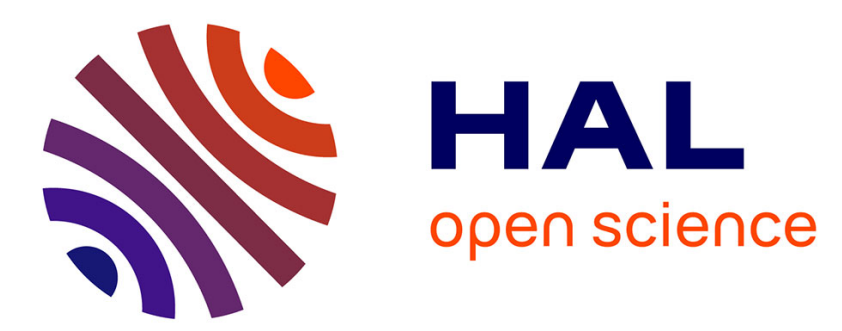

\title{
CALCULATION OF POPULATION INVERSIONS IN RECOMBINING LASER-PRODUCED ALUMINIUM PLASMAS
}

A. Klisnick, H. Guennou, J. Virmont

\section{- To cite this version:}

A. Klisnick, H. Guennou, J. Virmont. CALCULATION OF POPULATION INVERSIONS IN RECOMBINING LASER-PRODUCED ALUMINIUM PLASMAS. Journal de Physique Colloques, 1986, 47 (C6), pp.C6-345-C6-350. 10.1051/jphyscol:1986643 . jpa-00225887

\section{HAL Id: jpa-00225887 https://hal.science/jpa-00225887}

Submitted on 1 Jan 1986

HAL is a multi-disciplinary open access archive for the deposit and dissemination of scientific research documents, whether they are published or not. The documents may come from teaching and research institutions in France or abroad, or from public or private research centers.
L'archive ouverte pluridisciplinaire HAL, est destinée au dépôt et à la diffusion de documents scientifiques de niveau recherche, publiés ou non, émanant des établissements d'enseignement et de recherche français ou étrangers, des laboratoires publics ou privés. 
JOURNAL DE PHYSIQUE,

Colloque C6, supplément au $\mathrm{n}^{\circ} 10$, Tome 47, octobre 1986

C6-345

\title{
CALCULATION OF POPULATION INVERSIONS IN RECOMBINING LASER-PRODUCED ALUMINIUM PLASMAS
}

\author{
A. KLISNICK, H. GUENNOU and J. VIRMONT* \\ Laboratoire de Spectroscopie Atomique et Ionique, Bât. 350 , \\ Université Paris-Sud, F-91405 Orsay Cedex, France \\ and GRECO Interaction Laser-Matière, Ecole Polytechnique, \\ F-91128 Palaiseau Cedex, France \\ - Laboratoire de Physique des Milieux Ionisés, \\ and GRECO Interaction Laser-Matière, ECole Polytechnique, \\ F-91128 Palaiseau Cedex, France
}

\begin{abstract}
RESUME : Un code numérique hydrodynamique ainsi qu'un modèle collisionnel- radiatif atomique, couplé en post-processeur, sont utilisés pour calculer des inversions de populations qui apparaissent dans les ions lithumoides au cours de la recombinaison de plasmas d'aluminium produits par laser. On obtient ainsi l'évolution spatiale et temporelle des inversions $5 \mathrm{f}-3 \mathrm{~d}$ et $4 \mathrm{f}-3 \mathrm{~d}$ dans $\mathrm{Al}$. $\mathrm{L}^{\prime}$ étude de ces inversions, en fonction des caractéristiques du laser incident, fait ressortir un ensemble de valeurs optimales de paramètres du plasma (densité et température électroniques, abondance relative d'ions hélfumoídes et lithiumoīdes). On montre que la production de ces inversions dep population nécessite une intensité laser relativement modérée (de $1^{\prime}$ ordre de $5.10^{12} \mathrm{~W} / \mathrm{cm}^{2}$ ). Le role que jouent le refroidissement du plasma et le retard à la recombinaison des ions sur la production de ces inversions de population est mis en évidence.
\end{abstract}

ABSTRACT : A numerical hydrodynamics code post-processed by an atomic collisional-radiative model is used to calculate population inversions which occur in lithium-like lons in recombining aluminium laser-produced plasmas. Time and spatial evolution of the $5 \mathrm{f}-3 \mathrm{~d}$ and $4 \mathrm{f}-3 \mathrm{~d}$ population inversions in $\mathrm{Al}$ ire obtained. The investigation of these inversions according to a range of inctdent laser parameters emphasizes a set of optimal plasma values of electron density and temperature as well as relative abundance of He-like and Li-like ions. The laser flux density range required for the production of population inversions in $A 1$ is shown to be relatively moderate (about $5.10^{12} \mathrm{~W} / \mathrm{cm}^{2}$ ). The role of the cooling of the plasma and of the "frozen ionization" is emphasized.

\section{I - INTRODUCTION}

Both experimental /1-3/ and theoretical /4,5/ works have shown population inversions between $n=4,5$ and $n=3$ levels in lithium-like aluminium ions (Al ${ }^{\text {) }}$ to occyr in a recombining laser-produced plasma. In our group a gain value of about $2 \mathrm{~cm}^{-1}$ has been measured $/ 1 /$ at $105.7 \AA$, which is the wavelength of the $1 \mathrm{~s}^{2} 5 \mathrm{f} \rightarrow 1 \mathrm{~s}^{2}$ 3d transition in this ion. A collisional-radiative model, developed by $A$. Sureau and $H$. Guennou $/ 2,4 /$, has shown that the production of this $5 f-3 d$ population inyefsion was related to the strong recombining cascades in the high lying levels of $\mathrm{Al}{ }^{107}$, together with a very large radiative decay probability of the $3 \mathrm{~d} 1$ level. This scheme has been recently extended by the authors to other ions in the 1 ithium isoelectronic sequence. Calculated population inversions in $\mathrm{s}^{13+}$ are presented in a neighbouring paper $/ 6 /$. 
Calculation of inversion densities in realistic conditions have been carried out in this work, by using the model mentioned above in Al It as a post-processor of a ID - lagrangian hydrodynamical code (FILM) which includes a description of the ionization dynamics /7/. Time and spatial evolution of the $1 \mathrm{~s}^{2} \mathrm{n} 1$ excited level populations and of the inversion densities in the expanding plasma are obtalned. First calculations performed using incident laser conditions similar to the experimental ones have shown a good qualitative agreement between the time-variation of the $5 f-3 d$ inversion density on the one hand and the time-resolved measurement of gain at the wavelength of this transition $(105.7 \AA)$ on the other hand. In order to help for the cholce of the optimal experimental parameters for the production of gain, we investigated the evolutions of the $5 f-3 d$ as well as $4 f-3 d$ inversions according to a range of laser parameters (flux density, pulse duration) consistent with the Nd - glass laser at Palaiseau.

\section{II - STEPS OF THE CALCULATION}

\section{a) Collisional-radiative model :}

The model we have used for this study has been described elsewhere $/ 2,4 /$. We shall briefly recall its main characteristics. It includes 48 levels with $1 \mathrm{~s}^{2} \mathrm{n} 1$ configuration between $n=2$ and $n=7$ (figure 1). Levels $n=6$ and 7 , which form the thermal band $/ 8 /$, are assumed to be in LTE relative to the ground state ls of the helium-like aluminium ion (A1 ${ }^{1+}$ ). This $1 s^{2}$ population density as well 95 the $n=2$ $\left(1 s^{2} 2 \mathrm{~s}\right.$ and $\left.1 \mathrm{~s}^{2} 2 \mathrm{p}\right)$ quasidegenerate levels population densities in Al 107 are $\mathrm{fixed}$ according to the distribution of ionic species in aluminium, deduced from hydrodynamical simulations. Finally, the population of the intermediate levels ( $\mathrm{n}=$ 3,4 and 5) are calculated at each time and for each numerical cell of the simulation by solving a system of rate-equations. In the quasistationary approximation we can write for each level $i$ :

$$
0=(\mathrm{dNi} / \mathrm{dt})=\sum_{j>i} N_{j} A_{j i}+\sum_{j \neq i} N_{j} N_{e} C_{j i}-N_{i} \sum_{j<i} A_{i j}-N_{i j \neq i} \sum_{i j} C_{i j}
$$

where $\mathrm{N}_{t}$ is the population density of the $\mathrm{i}$ level; $\mathrm{N}$ is the electron density, deduced from the hydrodynamical simulations; A is the spontaneous radiative decay probability and $c_{j 1}$ is the collisional rate for the $j \rightarrow i$ transition.

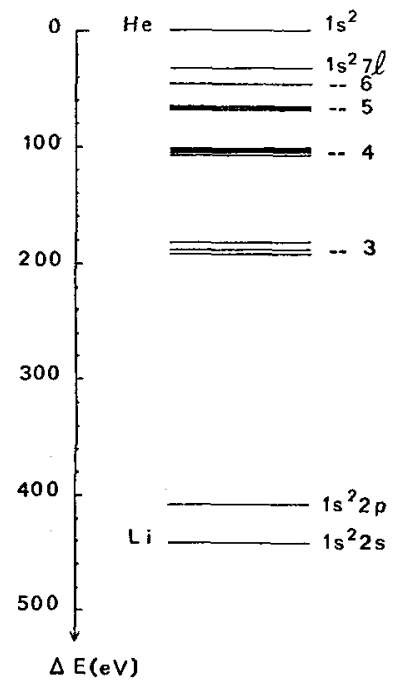

Figure 1: Energy diagram of the $1 \mathrm{~s}^{2} \mathrm{n} 1$ levels in the lithium-like aluminium ion. 


\section{b) Hydrodynamical simulations :}

In order to describe the evolution of a plasma column produced by line-focusing the laser beam on a plane massive target /1/, we have used the 10 hydrodynamical code FILM in a cylindrical geometry. In such a geometry the cylindrical target of infinite length is irradiated by the laser over all its surface (figure 2). The code provides values of electron density. $N$ and temperature $T$ as well as ionic fractions in aluminium. These quantities are then fed into the collisional-radiative model for Al I0t.



Figure 2: Cylindrical irradiation of the target for hydrodynamical simulations. In these results, $R_{t}=100 \mu m$.

As we mentioned, we are particularly interested in the evolution of two population inversions in A1 $10+$ : $5 \mathrm{f}-3 \mathrm{~d} \quad(\lambda=105.7 \AA)$ which is experimentally studied and $4 \mathrm{f}-3 \mathrm{~d}(\lambda=154.6 \AA)$ for which population inversions have been predicted $/ 3-5 /$. For the results presented here, we express the extent of the inversions by means of the inversion density $\Delta \mathrm{n} . \Delta \mathrm{n}$ is the difference between the reduced populations of the levels involved :

$$
\Delta \mathrm{n}_{\mathrm{ul}}=\left(\mathrm{N}_{\mathrm{u}} / \mathrm{g}_{\mathrm{u}}\right)-\left(\mathrm{N}_{1} / \mathrm{g}_{1}\right)
$$

where $\mathrm{N}_{\mathrm{u}}$ (resp. $\mathrm{N}_{1}$ ) is the population density and $\mathrm{g}_{\mathrm{u}}$ (resp. $\mathrm{g}_{1}$ ) is the statistical weight of the upper (resp. lower) level of the u-1 transition.

The quantity $\mathrm{n}$ is proportional to the gain coefficient $\mathrm{G}$ of the radiation at the wavelength of the inverted transition. The value of $G$ is dependent on the line profile which is itself a function of the plasma parameters (N, $T_{\text {) }}$. For the transitions under consideration in this study we can assume that the profele is dominated by thermal Doppler broadening, so that we can write :

$$
G(u \rightarrow 1) \simeq 8.410^{-23} \cdot g_{u} \cdot A_{u l} \cdot\left(\lambda_{u l}\right)^{3} \cdot\left(k T_{i}\right)^{-1 / 2} \cdot \Delta n_{u l}
$$

where $G$ is in $\mathrm{cm}^{-1} ; A_{\mathrm{ul}}$ is the spontaneous radiative decay probability for the $\mathrm{u} \rightarrow 1$ transition, in $\mathrm{ns}^{-1} ; \lambda$ ul is the $u \rightarrow 1$ transition wavelength, in $\AA$; $k T_{i}$ is the ionic temperature, in $\mathrm{eV} ; \Delta \mathrm{n}_{\mathrm{ul}}$ is in $\mathrm{cm}^{-3}$.

From (3), we can see that for the same inversion density $\Delta \mathrm{n}$ and ionic temperature $T_{i}$, the gain coefficient $G_{0}$ should be greater by ${ }_{1}$ fafctor of about ten for the $4 \mathrm{f}-3 \dot{d}$ 'inversion $\left(\lambda=154.6 \stackrel{\AA}{A}, A_{4 f-3 d} \stackrel{2}{\simeq} 200 \mathrm{~ns}^{-1}\right)$ than for the $5 \mathrm{f}-3 \mathrm{~d}$ inversion $\left(\lambda=105.7 \AA, A_{5 f-3 d} \simeq 50 \mathrm{~ns}^{-1}\right) .4 \mathrm{f}-3 \mathrm{~d}$

III - RESULTS

On figure 3, we present typical results of the calculations. Here the aluminium cylinder-target (radius $100 \mu \mathrm{m}$, initial surface at $\mathrm{R}=100 \mu \mathrm{m}$ ) was irradiated by a 2ns (FWHM) gaussian pulse of a $1.06 \mu \mathrm{m}$ laser with. $1.310^{12} \mathrm{~W} / \mathrm{cm} 2$ intensity. Figure 3.a represents the $5 f-3 d$ inversion density as a function of the distance to the target surface (in abscissa) and for several times between 5.5 and 10 ns when the top of the laser pulse occured at $t=2 n s$. One can see -and this is a general feature of the results- that the population inversion takes place in the corona of the plasma at the end of and after the laser pulse, that is in the recombination phase. At the present time, this is verified by experiment /9/. At 
early stage of the plasma expansion, during the laser pulse, this "inversion density" appears strongly negative, that is in the standard situation where $\mathrm{N}_{5 f} / \mathrm{g}_{5 \mathrm{f}} \ll \mathrm{N}_{3 \mathrm{~d}} / \mathrm{g}_{3 \mathrm{~d}}$

On figure $3 . b$ the $4 f-3 d$ inversion, which has the same lower level $3 d$, exhibits very similar evolution. Nevertheless, it can be seen that the decrease of the inversion maxima with time is more rapid in the case of the $4 \mathrm{f}-3 \mathrm{~d}$ transition. As a matter of fact, the radiative decay probability of the $4 f$ level is about three times larger than the $5 f$ 's one.
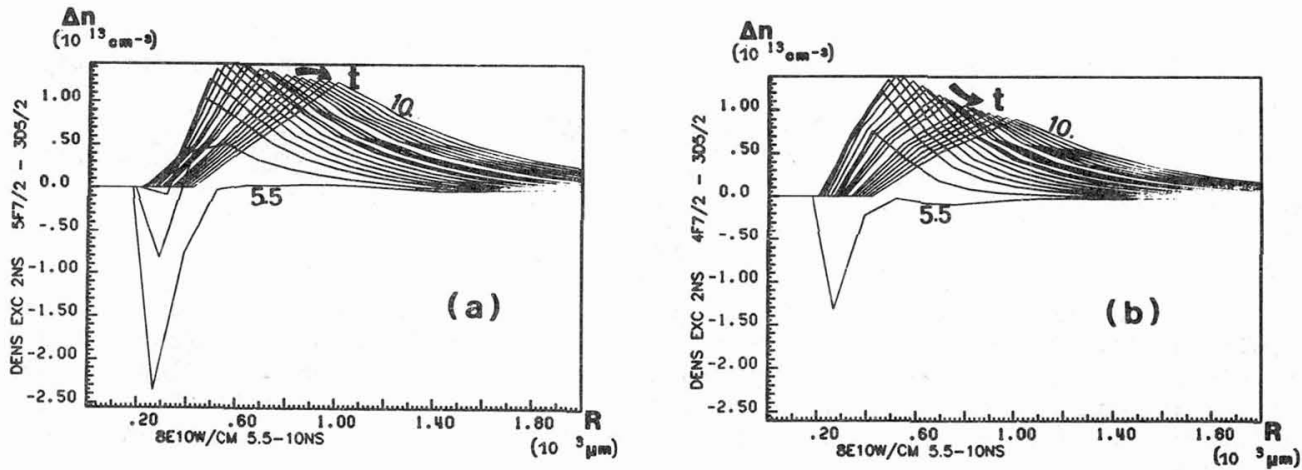

Figure 3: Time and spatial evolution of the 5f-3d (a) and 4f-3d (b) inversion densities, from $t=5.5 \mathrm{~ns}$ to $t=10 \mathrm{~ns}$ ( $\Delta t=250 \mathrm{ps}$ between each curve). Top of the laser pulse (2ns duration; $1.310^{\mathrm{F}} \mathrm{W} / \mathrm{cm}^{2}$ intensity; $1.06 \mu \mathrm{m}$ wavelength) at t=2ns. Initial target, surface: $R=100 \mu m$. The laser beam comes from the right.

\section{a) Effect of rapid cooling versus slow recombination :}

Time variation of the inversion densities $\Delta n(5 f-3 d)$ and $\Delta n(4 f-3 d)$ and of some plasma parameters are shown on figures $4 . a$ and $4 . \mathrm{b}$, at the point of maximum inversions in plasma ( $X=400 \mu \mathrm{m}$ from the initial target surface). Here the laser pulse duration is $600 \mathrm{ps}$ (FWHM) and the top of this pulse occurs at $t=600 \mathrm{ps}$ as pointed out by the arrow. The laser flux intensity is the same as in figure 3 . The peaks of inversion density occur at about $4 \mathrm{~ns}$, just when the lithium-1ike ions density is increased by helium-1ike ions recombination. In the same time, the plasma temperature goes down very rapidly, so that $A 1^{1+}$ and $A I^{10+}$ density values are well above their LTE values for this temperature. This "frozen ionization" is a common feature of laser-plasma corona. The relative over-abundance of He-like ions together with a low temperature contribute to strongly populate the levels in the thermal band of lithium-like ions. These levels are then able to populate the $n=4$ and $n=$ 5 levels through collisional and radiative cascades. At the time wheq the $5 \mathrm{f}-3 \mathrm{~d}$ and 4f-3d inversions are maximum the electron density is of about $1.210^{19} \mathrm{~cm}$ whereas the electron temperature has been decreasing to $20 \mathrm{eV}$. These values are characteristic of the optimal plasma parameters for the $5 \mathrm{f}-3 \mathrm{~d}$ and $4 \mathrm{f}-3 \mathrm{~d}$ inversions. Changing the laser pulse conditions doesn't affect them significantly. It can be noted that modelling work, performed on the recombining scheme in hydrogenic carbon $\mathrm{C}^{5+}(3-2$ transition at $182 \AA) / 10 /$, has given similar results relative to the optimal electron density and temperature. This is not surprising as the relevant energy level intervals are of the same order of magnitude in both cases. 



Figure 4: Time variation, at $400 \mu \mathrm{m}$ from the initial target surface, of:

(a): $5 \mathrm{f}-3 \mathrm{~d}(\longrightarrow$ and $4 \mathrm{f}-3 \mathrm{~d}(-)$ inversion densities.

(b): electron density value $(-)$ and temperature $(-+)$; He-like $(--)$ and Li-like (-o) ions density values.

Laser pulse duration: 600ps. Same intensity as in figure 3. The arrow points out the top of the laser pulse.
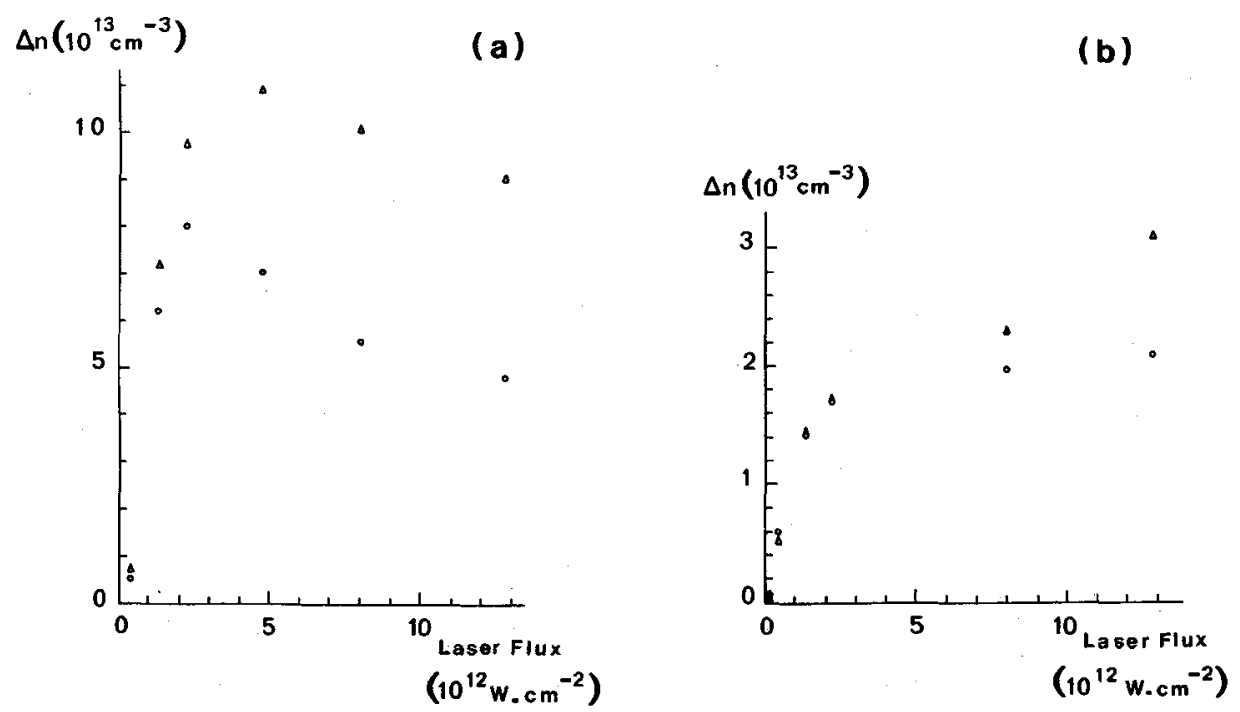

Figure 5: Role of the incident laser intensity on the absolute computed maximum of inversion density $((\bullet) 5 f-3 d ;(\Delta) 4 f-3 d)$. Laser wavelength: $1.06 \mu \mathrm{m}$. Pulse duration: (a)600ps; (b) $2 \mathrm{~ns}$. 


\section{b) Effect of laser-pulse intensity and duration :}

The computed absolute maximum of inversion density $4 \mathrm{f}-3 \mathrm{~d}$ and $5 \mathrm{f}-3 \mathrm{~d}$, as a function of the laser flux, for two different pulse durations, is shown in figure 5 . In the casf of a 600 ps pulse (fig. 5.a), the optimal power density is close to 4.8 $10^{12} \mathrm{~W} / \mathrm{cm}^{2}$ for both $4 \mathrm{f}-3 \mathrm{~d}$ and $5 \mathrm{f}-3 \mathrm{~d}$ inversions. At equal laser intensity, $600 \mathrm{ps}$ pulse appears to produce larger inversions densities than $2 \mathrm{~ns}^{\prime}$ one (fig. 5.b). This can be related to the fact that shorter pulses are more effective to induce departure from equilibrium in the distribution of ionic species in the plasma. However this prediction is still not confirmed by experiments.

\section{IV - CONCLUSION}

For all the laser-pulse parameters we used, the $5 f-3 d$ and $4 f-3 d$ inversions in $\mathrm{Al}^{10+}$ occur in the corona of the plasma ( $\left.\mathrm{R}>300 \mu \mathrm{m}\right)$ after the laser pulse, that is in the recombination phase of the plasma. At the present time this is verified by experiment for 5f-3d transition. The optimal plasma parameters corresponding to the absolute maximum of both inversions are $1-310^{19} \mathrm{~cm}^{-3}$ for the electron density $\mathrm{N}$ and $20-40 \mathrm{eV}$ for the electron temperature $\mathrm{T}$. He-1ike and Li-like aluminium ion densities are well above their LTE values for this temperature range.

$5 \mathrm{f}-3 \mathrm{~d}$ and $4 \mathrm{f}-3 \mathrm{~d}$ inversion densities increase as the laser intensity goes from $0.410^{12} \mathrm{~W} / \mathrm{cm}^{2}$ to $2.210^{12} \mathrm{~W} / \mathrm{cm}^{2}$, that is in the range available in our experiments. For 600 ps pulse, calculation shows a maximum of inversion dẹsity to occur at about $4.810^{12} \mathrm{~W} / \mathrm{cm}^{2}$. Population inversions in lithium-1ike Al $10+$ require relatively moderate laser intensity in comparison with other X-ray laser schemes.

600 ps pulse duration appears to produce larger inversion densities than 2 ns one. This prediction needs to be experimentally confirmed. Otherwise the model would have to take into account processes which are neglected at the present time. For example, we shall incorporate the transport of radiation to our modelling : radiative losses due to resonance lines emission and radiative recombination could strengthen the cooling of the plasma, whereas radiation trapping could influence the population of some excited levels.

\section{REFERENCES :}

/1/ P. Jaegle, G. Jamelot, A. Carillon, A. Klisnick, in this volume

/2/ G. Jamelot, A. Klisnick, A. Carillon, H. Guennou, A. Sureau and P. Jaegle, J. Phys. B 18 (1985) 4647.

/3/ E. Ya. Kononov, K.N. Koshelev, Yu A. Levykin, Yu. V. Sidel'Nikov and S.S. Churilov, Sov. J. Quant. Electron, 6,3 (1976) 308.

/4/ H. Guennou, thesis Orsay (1983)

/5/ E. Ya Kononov and K.N. Koshelev, Sov. J. Quant. E1., 4, 11 (1975) 1340

/6/ H. Guennou, A. Sureau and C. Möller, in this volume

/7/ J.C. Gauthier, J.P. Geindre, N. Granjouan and J. Virmont, J. Phys. D, 16 (1983) 321 .

/8/ R.W.P. McWhirter in Plasma Diagnostic Techniques, edited by R.H. Huddlestone and S.L. Leonard (1965), Academic Press New-York London.

/9/ P. Jaeglé, A. Carillon, A. Klisnick, G. Jamelot, H. Guennou and A. Sureau Europhys. Lett. 1 (1986) 555 .

/10/ D. Jacoby, G.J. Pert, L.D. Shorrock and G.J. Tallents, J. Phys. B, 15 (1982) 3557. 